\title{
Research on Evaluation System for Ship's Integrated Sailing Performance
}

\author{
Sun Shuzheng \\ College of Shipbuilding Engineering \\ Harbin Engeering University \\ Harbin City, China \\ e-mail: sunshuzheng@hrbeu.edu.cn \\ Ren Huilong \\ College of Shipbuilding Engineering \\ Harbin Engeering University \\ Harbin City, China \\ e-mail: renhuilong@263.net
}

\author{
Jiao Jialong \\ College of Shipbuilding Engineering \\ Harbin Engeering University \\ Harbin City, China \\ e-mail: jiaojialong@hrbeu.edu.cn
}

\author{
Li Jide \\ College of Shipbuilding Engineering \\ Harbin Engeering University \\ Harbin City, China \\ e-mail: ship104@163.com
}

\begin{abstract}
The integrated sailing performance is important to the ship design and manufacture. However, it is very hard to be evaluated objectively and reasonably. In this paper the evaluation system of integrated sailing performance of ship's was built which included seakeeping performance, wave loads, speed and stability performance in waves. The main characters were picked out and considering the influence of wave environment to build the evaluation system. AHP method was used to get the weight factors, and then the evaluation system could be built. So, the effects of wave and wind could be considered in the evaluation system. And then the evaluation system would be better than the single performance evaluation system and the evaluation system in calm water. The research of this paper is important to the integrated sailing performance evaluation system and evaluating method, which laid the foundation for the next step in the establishment of the comprehensive navigation performance evaluation equation for the ships in the waves.
\end{abstract}

Keywords- integrated sailing performance of ship's; wave ; evaluation system; index; AHP method

\section{INTRODUCTION}

The comprehensive navigability of the ship in waves has always drawn attention from the shipbuilding circles. With the concepts of energy conservation and environment protection as well as green shipbuilding deepening, people show more interest in the comprehensive navigability of the ship. However, the ship navigates at sea, which may be affected by waves during the process of navigation, so it is uncertain for the ship with an excellent navigability in the still water to possess equal performance in waves. The motion performance of the ship in waves is quite different from that in the still water. The ship motion caused due to stormy waves will bring great adverse effect on the work of people and use of equipment on the ship, reducing the comprehensive operating efficiency of the ship by a large margin. International Maritime Organization (IMO) stipulates that Energy Efficiency Design Index (EEDI) has been applied to new ships since 2013. The calculation formula of EEDI takes the influence of waves on the navigational speed into account, but many transport ships of our country fail to meet the average index. Once it is applied, it will make domestic ship industry suffer from a great loss, putting forward higher requirements on the comprehensive navigability of domestic ships in waves.

Currently, the evaluation systems on the navigability of the ship mainly focus on the still water and seldom consider the influence of waves, besides, most evaluation systems are established based on single performances, such as rapidity, seakeeping, and control ability and so on, forming a big gap with the actual comprehensive navigability of the ship. This paper establishes a comprehensive navigability index system of the ship in waves by taking various performance parameters of the ship in waves as characteristic parameters. Then, it adopts analytic hierarchy process (AHP) to make an analysis on each evaluation index by analytic hierarchy in classification to determine the parameters of each characteristic and the weights of each single index, so as to establish the comprehensive navigability index system of the ship in waves.

\section{SELECTION OF EVALUATION INDEXES}

Through analyzing the influence of each single index on the navigability of the ship and its task, etc. to select the seakeeping, wave load, rapidity and stability in waves and other properties based on the principles of completeness, independence, simplicity, scientificalness and operability according to the degree of influence, while each index contains a number of related characteristic parameters, and then, to reasonably select those with great influence on the system performance as evaluation indexes through analysis.

\section{A Rapidity Index}

The rapidity of the ship refers to the ability of navigating at a certain speed under rated power of the engine. Generally, it includes ship resistance and ship propulsion. Admiralty coefficient ${ }^{[3]}$ is an important 
parameter measuring the rapidity of the ship, including general information of the ship's good or bad performance of resistance and propulsion, and also a comprehensive evaluation factor for the rapidity of the ship. The formula of admiralty coefficient is as follow:

$$
C_{s p}(x)=\Delta^{-2 / 3} \cdot V_{s}^{-3} \cdot P_{E} /\left(\eta_{O} \cdot \eta_{H} \cdot \eta_{R}\right)
$$

where: $\Delta-$ Displacement;

$V_{s} \longrightarrow$ Speed in waves;

$P_{E}$ Efficient power;

$\eta_{O}$ Efficiency of propeller in open water;

$\eta_{H}-$ Efficiency of ship hull;

$\eta_{R} \longrightarrow$ Ralative rotary efficiency;

Refer to the admiralty coefficient the speediness indexs were taken as follows: Speed in waves, Efficiency of propeller in open water, Efficiency of ship hull, and Ralative rotary efficiency.

\section{B. Seakeeping Index}

The seakeeping of the ship is determined by multiple fundamental seakeeping factors. At present, it is generally recognized at home and abroad that seakeeping factors include 6-DOF motion, linear (angular) speed, and linear (angular) acceleration, seakeeping incidents like water on deck, propeller emergence, bow slamming and so on, and the rate of seasickness. As mentioned above, the seakeeping criterion of the ship has a direction relation with the type, task, personnel quality and functions of systems (equipment) of the ship. Different tasks require different systems to work normally and effectively, so it is difficult to set an absolutely unified criterion for each seakeeping factor. Therefore, to reduce factors in discussion through combining compatible items and eliminating items with less effect according to the circumstances. According to the result of materials I have searched, survey on the navigator and performance of the ship, this paper selects six seakeeping factors for the comprehensive evaluation equation of seakeeping, namely rolling, pitching, heaving, bow section slamming at one station, water on deck and vertical acceleration of bow.

\section{Stability Index}

The stability of the ship refers to the ability of returning to the original balanced position from the tilted position resulting from the force of external torque after it disappears. Static stability can be measured by the size of the restoring torque, while dynamic stability needs to be measured by the work of restoring torque. Both of them are variables, and affected by water discharge, stability height and roll angle of the ship. Although all ships built go through the test conducted by the administration of ships survey before launching, and put into service after confirming to meet the stability standard, since there is a close relation between the transverse stability of ships and the complex marine environment, ships motion, operation and other factors, while the weather criterion in the existing stability standard is a quasi-dynamic method based on the stability of ships in the still water and statistical information. Thus, there are obviously problems which need to be improved, including how to describe the effects of wind, wave and flow on the ship correctly. According to the research on ship stability in Chapter 1 and referring to the stability standard, this paper selects the ability of wind resistance of the ship in stormy waves as the evaluation index.

\section{Wave Load Index}

The longitudinal strength is mainly considered when selecting performance indexes of ${ }^{[5]}$ the wave load. Generally, the analysis on longitudinal strength of the ship contains two parts, including joint normal stress check and shearing stress check when longitudinal bending and ultimate stress check. The former two sections intend to discuss the strength of ship when navigating in the normal state, while the latter part intends to discuss the strength reserve of ship in the unexpected state. Ships may suffer from various unexpected conditions when using, such as stranding, collision, underwater explosion and so on. Since it is difficult to determine the external load applied on the ship at this time, generally, the ultimate bending moment is adopted to evaluate the carrying capacity of ship structure.

From the existing specification for ship of our country, the definition of ultimate bending moment $M_{u}$ refers to that in the flange plate of beam away from the cross section and axis at utmost when internal stress reaches severe stress (for stretching situation, it refers to the yield limit of materials $\sigma_{s}$; while for compressing situation, it refers to the critical stress of grillage $\sigma_{c r}$ ). That is:

$$
\left\{\begin{array}{l}
\text { Saggin } \quad M_{u}=\min \left(\sigma_{c r \text { deck }} W_{1 \text { deck }}, \eta_{1} \sigma_{\mathrm{s}} W_{1 \text { hull bottom }}\right) \\
\text { Hogging } M_{u}=\min \left(\sigma_{c r \text { hull bottom }} W_{2 \text { hull bottom }}, \eta_{2} \sigma_{\mathrm{s}} W_{2 \text { deck }}\right)
\end{array}\right.
$$

In the formula: $W_{1 \text { deck }}$ And $W_{1 \text { hull bottom }}$-- are the section moduli of deck and hull bottom when sagging respectively;

$W_{2 \text { deck }}$ and $W_{2 \text { hull bottom }}$--respectively are the section modulus of the deck and hull bottom under hogging condition (when calculating the modulus mentioned above, the effect of the losing stability of parts of panels should be taken into account under the compressive stress);

$\sigma_{c r \text { deck }}$ and $\sigma_{c r \text { hull bottom }}$-- respectively are the critical stresses when the plate frame of the deck and ship bottom is under the overall bending;

$\eta_{1}$ and $\eta_{2}$-- respectively are the ratio between the distance from the hull girder tensile flange plate to the neutral axis and the distance from the compression wing plate to the neutral axis in the sagging condition and the hogging condition(when the ratio is more than 1,1 is taken).

The ultimate strength conditions are usually shown by the non-dimensional ratio between the limit bending moment and the maximum external bending moment when in the normal navigation. That is, it must meet whether in the vertical state or the hogging condition: 


$$
\frac{M_{\mathrm{u}}}{M_{s}+M_{w}} \geq m
$$

式中: $M_{s}-$ moment in calm water;

$M_{w}-$ moment in waves;

$M_{\mathrm{u}}$ extreme moment;

In this article, the effects of the strength are taken into consideration comprehensively, and the ultimate strength conditions are chosen as the wave load evaluation index.

\section{DETERMINATION OF THE WEIGHT OF EACH INDICATOR}

\section{A Analytic Hierarchy Process}

AHP--Analytic Hierarchy Process ${ }^{[8]}$ is a method to analyze the problems proposed by T.L. Satty of University of Pittsburgh in United States in 1970s. The results calculated by using the AHP algorithm eventually are a set of coefficients or the relative ordering. As the weight coefficients, they can be directly used into the model for calculation, such as the weight coefficients in the model of "weighted sum" etc.; as the relative ordering among the schemes, it itself can be used for the decision.

The characteristics of AHP are that it has the clear ideas, and it does not need too much quantitative data and is applicable to the analysis with the multi criteria and multiple objectives. The use steps include: defining the problem, setting up the hierarchy structure, establishing the judgment matrix of each level, single taxis of hierarchy and total taxis of hierarchy. AHP requires to give the judgment on the mutual importance of each element in each level, and to show the findings in the numerical form written in the matrix form. The following judgment matrix can be structured by comparing the relative importance of per two-indicator in the indexing set. See Table 1:

TABLE I. JUDGMENT MATRIX STRUCTURE

\begin{tabular}{cccccc}
\hline$R$ & $A_{1}$ & $A_{2}$ & $\cdots$ & $\cdots$ & $A_{\mathrm{n}}$ \\
\hline$A_{1}$ & $a_{11}$ & $a_{12}$ & $\cdots$ & $\cdots$ & $a_{1 \mathrm{n}}$ \\
\hline$A_{2}$ & $a_{21}$ & $a_{22}$ & $\cdots$ & $\cdots$ & $a_{2 \mathrm{n}}$ \\
\hline$\cdots$ & $\cdots$ & $\cdots$ & & & $\cdots$ \\
\hline$\cdots$ & $\cdots$ & $\cdots$ & & & $\cdots$ \\
\hline$A_{\mathrm{n}}$ & $a_{\mathrm{n} 1}$ & $a_{\mathrm{n} 2}$ & $\cdots$ & $\cdots$ & $a_{\mathrm{nn}}$ \\
\hline
\end{tabular}

Among them, the $a_{\mathrm{ij}}$ means to $R$, the importance of $a_{\mathrm{i}}$ to $a$ $\mathrm{j}$. In AHP, the evaluation of $a_{\mathrm{ij}}$ adopts 1, 3, 5, 7, 9 scaling method, making the comparison between two elements quantized. After the establishment of judgment matrix, the normalized processing and the consistency check are also needed. Set $a_{i j}=f\left(u_{i}, u_{j}\right)$, then the judgment matrix should have the following characteristics:

$$
a_{i i}=1
$$

$$
\begin{gathered}
a_{i j}=\frac{1}{a_{j i}} \quad(i, j=1,2, \mathrm{~L}, n) \\
a_{i j}=\frac{a_{i k}}{a_{j k}} \quad(i, j, k=1,2, \mathrm{~L}, n)
\end{gathered}
$$

In order to make all the analysis findings reasonable, after constructing the judgment matrix, the consistency of the judgment matrix needs to be checked to ensure the too great deviation will not occur. That is, as for the judgment matrix, the following formula should be met when calculating:

$$
A W=\lambda_{\max } W
$$

Among them, the $A$ is the judgment matrix, $\lambda_{\max }$ is the greatest characteristic root of the matrix $A$, and the $W$ is the corresponding standardized eigenvector of $\lambda_{\max }$. After the normalized processing, it is the single taxis of hierarchy values (the weights) of the relative importance of the corresponding influence factors in the level to the last hierarchy factors. The consistency check of the single taxis of hierarchy is calculating the deviation consistency indexes:

$$
C I=\frac{\lambda_{\max }-n}{n-1}
$$

Among them, $C I$ is the consistency index, and the $n$ is the order number of the judgment matrix. When the random consistency ratio is:

$$
C R=\frac{C I}{R I}<0.10
$$

Then it is thought that the findings of the single taxis of hierarchy have the satisfactory consistency, that is, the judgment matrix $A$ meets the requirement of consistency, if not, the judgment matrix needs to be adjusted to make it possess the satisfactory consistency. Among them, the RI is the random consistency index; its value can be obtained by looking up the table.

After judgment matrix possesses the satisfactory consistency, the corresponding eigenvectors after the normalization can be taken as the normalized weight values $\lambda_{\max }$.

\section{B. The establishment of the index weight judgment matrix}

The two-level index system is created by using AHP, taking the four performances-rapidity, seakeeping, stability and the wave loads as level 1 index, as shown in Table 2; The different evaluation indexes in each single performance are taken as level 2 indicators, and judgment matrices are respectively created according to the relative importance degree of each indicator, as shown in Table 3 and Table 4:

\section{TABLE II. JUDGMENT MATRIX OF SAILING PERFORMANCE}

\begin{tabular}{ccccc}
\hline$A$ & $A_{1}$ & $A_{2}$ & $A_{3}$ & $A_{4}$ \\
\hline$A_{1}$ & 1 & $1 / 3$ & $1 / 5$ & 1 \\
\hline$A_{2}$ & 3 & 1 & $1 / 2$ & 3 \\
\hline$A_{3}$ & 5 & 2 & 1 & 5 \\
\hline$A_{4}$ & 1 & $1 / 3$ & $1 / 5$ & 1
\end{tabular}

In the Tables, $A_{1}$ - stability, $A_{2}$ - rapidity, $A_{3^{-}}$seakeeping, $A_{4^{-}}$the wave loads. The eigenvectors after being calculated and normalized $W=(0.0994,0.28397,0.51794$, 
$0.0994)^{T}$ the random consistency ratio $C R=0.00156<$ 0.10 , which meet the requirement of consistency.

\section{TABLE III. JUDGMENT MATRIX OF SPEEDINESS}

\begin{tabular}{ccccc}
\hline$A_{2}$ & $w_{1}$ & $w_{2}$ & $w_{3}$ & $w_{4}$ \\
\hline$w_{1}$ & 1 & 5 & 5 & 5 \\
\hline$w_{2}$ & $1 / 5$ & 1 & 1 & 1 \\
\hline$w_{3}$ & $1 / 5$ & 1 & 1 & 1 \\
\hline$w_{4}$ & $1 / 5$ & 1 & 1 & 1 \\
\hline
\end{tabular}

In the Tables: $w$ 1- the navigational speed in waves, $w 2-$ open water efficiency of the propeller, w 3- hull efficiency, $\mathrm{w} 4-$ the relative rotation efficiency. The eigenvectors after being calculated and normalized W $2=(0.625,0.125$, $0.125,0.125) \mathrm{T}$ the random consistency ratio $\mathrm{CR}=0<0.10$, which meet the requirement of consistency.

TABLE IV. JUDGMENT MATRIX OF SEAKEEPING

\begin{tabular}{lllllll}
\hline $\mathrm{A} 3$ & $\mathrm{u} 1$ & $\mathrm{u} 2$ & $\mathrm{u} 3$ & $\mathrm{u} 4$ & $\mathrm{u} 5$ & $\mathrm{u} 6$ \\
\hline $\mathrm{u} 1$ & 1 & $1 / 3$ & 1 & 2 & 3 & 5 \\
\hline $\mathrm{u} 2$ & 3 & 1 & 3 & 2 & 5 & 6 \\
\hline $\mathrm{u} 3$ & 1 & $1 / 3$ & 1 & 2 & 3 & 5 \\
\hline $\mathrm{u} 4$ & $1 / 2$ & $1 / 2$ & $1 / 2$ & 1 & 3 & 5 \\
\hline $\mathrm{u} 5$ & $1 / 3$ & $1 / 5$ & $1 / 3$ & $1 / 3$ & 1 & 2 \\
\hline $\mathrm{u} 6$ & $1 / 5$ & $1 / 6$ & $1 / 5$ & $1 / 5$ & $1 / 2$ & 1 \\
\hline
\end{tabular}

In the Tables: $\mathrm{u}$ 1- the pitching, $\mathrm{u}$ 2-cross rolling, $\mathrm{u} 3$ fluctuations, $\mathrm{u}$ 4- the vertical acceleration of the bow, $\mathrm{u} 5$ the section attack on the bow one station, $\mathrm{u} 6$-the water on deck. The eigenvectors after being calculated and normalized W $3=(0.18841,0.37121,0.18841,0.14962$, $0.06359,0.03876) \mathrm{T}$ the random consistency ratio $\mathrm{CR}=0.03322<0.10$, which meet the requirement of consistency.

\section{THE CRITERIA VALUES OF EACH INDICATOR}

\section{A. The criteria of rapidity}

Due to the existing resistance added by the waves, a certain speed loss occurs when the watercrafts sailing in the wind and waves. Taking the navigational speed in still water as the criterion, the comparison between the actual speed of the ship and the criterion value under the same main engine power is conducted.

\section{$B$. The criteria values of the seakeeping}

As for the criteria values of the seakeeping, there are different suggestions from different organizations as well as different scholars ${ }^{[1]}$, and this article adopts a set of criteria values of the seakeeping proposed by China Ship Scientific Research Center, as shown in Table 5:

\begin{tabular}{llll}
\hline No. & $\begin{array}{l}\text { Seakeeping performance } \\
\text { factors }\end{array}$ & $\begin{array}{l}\text { Criteria } \\
\text { value }\end{array}$ \\
\hline 1 & $\begin{array}{l}\text { Significant pitching angle } \\
\psi_{a 1 / 3}\end{array}$ & $4.8^{0}$ \\
\hline 2 & $\begin{array}{l}\text { Significant rolling angle } \\
\theta_{a 1 / 3}\end{array}$ \\
\hline 3 & sickness (in 2hours) $\%$ & 30 \\
\hline 4 & $\begin{array}{l}\text { Significant vertical } \\
\text { acceleration g }\end{array}$ \\
\hline 5 & $\begin{array}{l}\text { Slamming times in 100 } \\
\text { times }\end{array}$ \\
\hline 6 & $\begin{array}{l}\text { Green water times per } \\
\text { minute }\end{array}$ & 0.5 \\
\hline 7 & $\begin{array}{l}\text { Propeller out of water } \\
\text { times per minute ( 25 } \%\end{array}$ \\
blade)
\end{tabular}

\section{The criteria of stability}

According to the ship stability requirements by the stability norms ${ }^{[17]}$, the wind resistant capability of the ships in the water can be divided into 6 levels according to the wind scale that the ship can resist. See in Table 6.

\begin{tabular}{ccc} 
TABLE VI. & \multicolumn{2}{c}{ CLASSES OF STABILITY OF SHIPS } \\
\hline $\begin{array}{c}\text { Stability } \\
\text { Class }\end{array}$ & $\begin{array}{c}\text { Wind } \\
\text { Class }\end{array}$ & $\begin{array}{c}\text { Speed of wind } \\
(10 \mathrm{~m} \text { heigh } \\
\text { position }) \mathrm{m} / \mathrm{s}\end{array}$ \\
\hline 1 & 12 & 52 \\
\hline 2 & 11 & 46 \\
\hline 3 & 10 & 40 \\
\hline 4 & 9 & 35 \\
\hline 5 & 8 & 31 \\
\hline 6 & 6 & 21
\end{tabular}

The wind resistant level of the ships in water with the normal drainage volume should accord with the provisions of Table 7 .

TABLE VII. WIND RESISTANT LEVEL OF SHIPS

\begin{tabular}{cccc}
\hline Displacement $\Delta / \mathrm{t}$ & $2500 \leq \Delta$ & $\begin{array}{c}1000 \leq \Delta \\
<2500\end{array}$ & $\begin{array}{c}200 \leq \Delta \\
<1000\end{array}$ \\
\hline Wind class & 12 & 11 & 10 \\
\hline
\end{tabular}

The wind resistant capability of the ships in water should accord with the formula:

$$
U_{1} \geq U_{0}
$$

In the formula:

$U_{1}$ the limit wind speed that the ship can bear, $\mathrm{m} / \mathrm{s}$

$U_{0} \longrightarrow$ the rated gust wind speed that the ship can bear, $\mathrm{m} / \mathrm{s}$

The limit wind speed $U_{1}$ that the ship can bear (from a height $10 \mathrm{~m}$ above the water); can be calculated by the following formula: 


$$
U_{1}=C \cdot C_{\mathrm{h}} \sqrt{\frac{I_{C} \cdot \Delta}{A_{v} \cdot Z}}
$$

In the formula: $C$ coefficient, $C=115.5$; $C_{\mathrm{h}}$ - The correction coefficient of the wind speed distributed along the height, when $Z_{v}>3.5 \mathrm{~m}$, $C_{h}=\left(10 / Z_{v}\right)^{1 / 8} ;$ and $Z_{v} \leq 3.5 m, C_{h}=1.140$;

$I_{C}-$ The minimum capsizing lever of the ship, $\mathrm{m}$

$\Delta-$ Calculating and checking the drainage volume in the loading state, $\mathrm{t}$;

$A_{v}$ The area exposed to the wind, $\mathrm{m}^{2}$

$Z$ Calculating the wind action arm, m; as for the combat vessels, taking $Z=Z_{v}$;

$Z_{v} \longrightarrow$ he distance from the shape center of the

area exposed to the wind to the waterline, $\mathrm{m}$ 。

When conducting the evaluation of the wind and waves environment adaptability aiming at a particular ship, the wind resistance level should be designated according to its drainage volume.

\section{The wave loads criteria}

According to the Ship General Specification ${ }^{[9]}$, the ultimate strength conditions of the given ship should meet

$$
\frac{M_{u}}{M_{s}+M_{w}} \geq 2.6
$$

Then, the evaluation system could be discribed in the following graph:

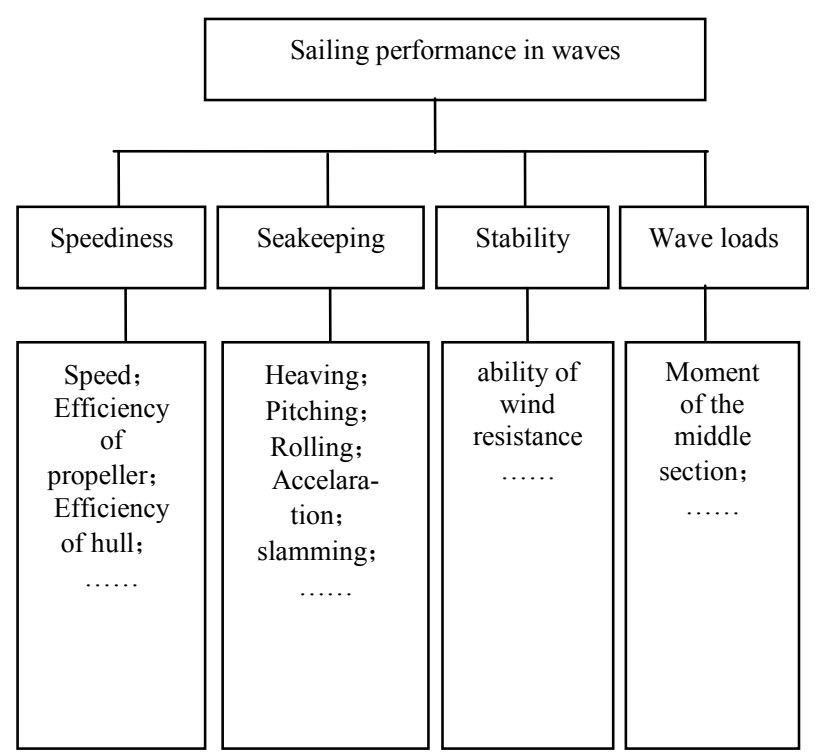

Figure 1. Structure Graph of Evaluation System

\section{CONCLUSION}

This article took the ship seakeeping, the wave load, rapidity and stability in the waves as well as the single characteristic parameters contained in each performance as the comprehensive navigation performance evaluation indexes for the ships in the waves, established the twolevel index judgment matrix by using the AHP, obtained the weights of each indicator and determined the criteria for each indicator, which laid the foundation for the next step in the establishment of the comprehensive navigation performance evaluation equation for the ships in the waves.

\section{ACKNOWLEDGMENT}

The author thanks the anonymous reviewers for their valuable remarks and comments. This work is supported by National Natural Science Fund of China (Grant No.51 209054), National Defense Foundation (9140A14030811 CB01), Basic Research Foundation of HEU(HEUCFR1 201).

\section{REFERENCES}

[1] Yang Songlin, Zhu Renqing, Wang Zhidong,etc. On the overall optimization of speed and maneuverability performance of largesize medium-speed ships. SHIP\&BOAT. No.5,Oct,2003,pp.18-23

[2] Munehiko Minoura and Shigeru Naito. A Stochastic Model for Evaluation of Seakeeping Performance. Proceedings of The Fourteeneh International Offshore and Polar Engineering Conference, Youlon, France, May,, 2004,pp.331-339

[3] Kadir Sario"z, Ebru Narli Effect of criteria on seakeeping performance assessment. Ocean Engineering, Vol.32, 2005, pp. 1161-1173

[4] Günther F Clauss. DETERMINISTIC SEAKEEPING TESTING TECHNIQUE FOR THE EVALUATION OF EXTREME MOTIONS AND LOADS ON MARINE STRUCTURES. International Conference in Marine Hydrodynamics, 2006 pp. 327 358

[5] Li Jide. Seakeeping Perfoemance of Ships. Press of Harbin Engineering University. 2003

[6] Xiong Wenhai, Mao Xiaofei, Li Yujiang. Review on Evaluation Met hods and Criteriafor Sea2keeping of Ships. SHIP\&OCEAN ENGINEERING. Vol.36 Aug. 2007.pp. 42-45

[7] Feng Baiwei, Liu Zuyuan, Chang Haichao. Calculation environment for warship's mutidisciplinary design optimization. SHIP\&BOAT. No.2, 2009. pp.5-8

[8] LI Huawen, LI Jing. Fuzzy comprehensive evaluation of ship's seaworthiness. Journal of Dalian Maritime University. Vol.32 No.4 Nov.2006 pp.54-57

[9] ZHAN G Huo-ming, YAN G Song-lin, ZHU Ren-qing, WA NG Zhi-dong. Fuzzy-genetic Algorithm of Ship Navigation Performance Optimization. Ship Building of China. Vol.43 No.3 Sep.2002 pp.7-14

[10] Dai Yangshan, Shen Jinwei, Song Jingzheng. Waveloads of Ships. Press of National Defence Industry, 2007 